\title{
Evaluation of a Web-based introductory psychology course: II. Contingency management to increase use of on-line study aids
}

\author{
WILLIAM S. MAKI and RUTH H. MAKI \\ Texas Tech University, Lubbock, Texas
}

\begin{abstract}
In a Web-based general psychology course, students were observed to postpone use of on-line study aids until 2 days prior to examinations, thus negating any influence of advance organizers (Taraban, Maki, \& Rynearson, 1999). We attempted to modify this behavior by providing course credit in the form of short quizzes as rewards for using on-line study aids to preview each chapter. Some students received quizzes after previewing frequently asked questions (FAQ); other students received quizzes after previewing chapter outlines. Students who received quizzes for previewing FAQ pages accessed those pages more frequently than did students who received quizzes for previewing outline pages. Increased access to FAQs was associated with higher scores on FAQ-related midterm examination questions. However, the advantage on examination items was not apparent on a cumulative final examination. Navigational structures and reward values need to be considered when one is managing contingencies in Web courses.
\end{abstract}

There is now a widespread belief that information technology will improve student learning, increase access to higher education, and even help colleges and universities control costs (e.g., Bork, 1997; Dede, 1996; Twigg, 1999). In parallel, institutions of higher education continue to invest in computers and related technology and are increasingly using such technology to conduct educational activities at a distance. Unfortunately, these developments are outpacing the rate of research on cognitive and behavioral outcomes of technology-mediated education. For example, the authors of recent reviews of hypermedia (Dillon \& Gabbard, 1998) and distance learning (Merisotis \& Phipps, 1999) could discover few wellcontrolled experiments. The World-Wide Web (Web for short) is a set of technologies rooted in both hypermedia and distance learning that is being used for delivery of educational experiences both on and off campus. Like its parent technologies, the educational use of the Web suffers from a lack of well-controlled research. We know rather little about how educational use of the Web influences student behaviors and learning outcomes.

The study described in this paper is part of a larger research project aimed at providing data on student learning and satisfaction in a Web-based general psychology course (beginning with W. S. Maki \& R. H. Maki, 1997). In a companion article in this issue (R. H. Maki, W. S. Maki, Patterson, \& Whittaker, 2000), we report learning

Support for development and evaluation of the Web course was provided by National Science Foundation Grant DUE 9752349 to R.H.M. and W.S.M. Correspondence concerning this article should be addressed to either W. S. Maki or R. H. Maki, Department of Psychology, Texas Tech University, Lubbock, TX 79409-2051 (e-mail: bill.maki@) ttu.edu or ruth.maki@ttu.edu). and satisfaction in the Web-based course in comparison with that in a lecture-based course. Students enrolled in a freshman general psychology course were taught with either of two methods. Some of the students were taught with the traditional lecture-test method. The remaining students were taught with materials distributed on the Web in place of lectures. During the academic year, the course was organized into eight Web sections and four lecture-test sections. In each of two semesters, each of two instructors was responsible for two Web sections and one lecture section. Thus, four Web sections and two lecture sections of the course were conducted each semester. The textbook and test items were both held constant across Web and lecture sections. We found that students in the Web sections learned more than did students in the lecture sections, and this learning outcome generalized across instructors and semesters. However, the students in the Web sections tended to be less satisfied than the students in the lecture sections; unlike the learning outcome, the satisfaction ratings varied with instructor and semester. (See R. H. Maki et al., 2000, for additional details.)

The narrower focus in the present article is on effects of instructional contingencies on student on-line study behaviors, and on how such behaviors affect student learning. The present study was motivated by the report by Taraban, W. S. Maki, and Rynearson (1999), who compared student study behaviors across three college courses that varied in technology use. One course was taught with the traditional lecture-test method. The lectures in the second course were supplemented with computer-based exercises. The third type of course was a version of the Web course reported in R. H. Maki et al. (2000). In all three types of courses, students reported that most of their study time was spent in the 2 days just prior to an examination. Inspection 
of electronic artifacts such as e-mail archives confirmed the students' reports. In the Web course, students used the Web to take on-line quizzes for course credit. Their quiztaking occurred mostly during the 2 days prior to each week's due date. However, their use of on-line study aids (such as chapter outlines and frequently asked questionsFAQs) was confined to the 2 days prior to the examinations given every 3 weeks. Thus, the students did not use the study aids for the purposes intended by the course designers (as advance organizers). Instead, they used them for last-minute reviews. Such "cramming" behaviors, as noted by Taraban et al. (1999), are counterproductive for learning.

In the present study, we asked whether modifying students' allocation of on-line study time is possible and, if so, what effect it might have on learning. Some students received short quizzes as rewards for previewing FAQ pages, and other students received short quizzes as rewards for previewing chapter outline pages. We predicted that use of FAQ pages should be elevated in the FAQ reward condition and that use of chapter outline pages should be elevated in the outline reward condition. Also, we predicted that students rewarded for use of FAQ pages would show increased performance on examination questions that specifically addressed FAQ-related topics.

\section{METHOD}

\section{Design}

The present experiment was conducted concurrently with the one reported in the companion article ( $R$. H. Maki et al., 2000). The overall project was designed so that we could study learning and satisfaction in Web and lecture sections, and, simultaneously using the same group of participants, explore variables that influence student on-line study behaviors by treating Web sections differently. Thus, the design of this experiment was embedded within the design of the one reported in the companion article. As in R. H. Maki et al. (2000), each of two instructors taught two Web sections and one lecture section in each of two semesters. During each semester, the two Web sections taught by each instructor were assigned randomly to two reward conditions. In one condition, short quizzes were used as rewards for studying FAQ pages; in the other condition, short quizzes were used as rewards for studying chapter outline pages.

\section{Participants}

Participants were students at Texas Tech University in the fall and spring semesters of the 1998-1999 academic year who were enrolled in general psychology (four Web sections and two lecture sections each semester). The Web sections were advertised as such in the schedule of classes, and students in the Web sections were informed of our data collection efforts. Initial enrollments across the academic year totalled 151 in the Web sections and 182 in the lecture sections. Final enrollments were 130 for the Web sections and 175 for the lecture sections. (See R. H. Maki et al., 2000, for additional demographic details.)

\section{Procedure Common to Lecture and Web Sections}

The lecture and Web sections were assigned a common textbook and took common midterm and final examinations. Two graduate assistants served as instructors, each of them responsible for one lecture section and two Web sections. Both lecture and Web sections covered the material in the textbook at the rate of 1 chapter per week, 13 chapters in all.
For examination purposes, the course was divided into four units. Each of the first three units covered three chapters and was followed by a midterm examination. The final examination covered the four chapters in the fourth unit and also (cumulatively) covered the preceding three units. Each of the first three middterm examinations contained 44-45 multiple choice questions drawn from the test bank provided by the textbook publisher. The fourth unit tests contained 45-47 questions. The cumulative part of the final examination contained 37 questions.

\section{Procedure for Lecture Sections}

The lecture sections met three times per week for an in-class lecture. Other than an optional printed study guide, the textbook and lectures were the sole materials available to the students in the lecture sections. The format of the lecture sections was the same as that used in previous years by graduate assistants instructing in General Psychology.

\section{Procedure for Web Sections}

In the Web sections, the lectures were replaced by three required activities. Each week, students took mastery quizzes, performed lab-like interactive assignments, and met once in class for a discussion or demonstration. The quizzes and assignments were administered on the Web. Students performed this unproctored course work at self-determined times and places (usually in their residences or in computer facilities at the university). Completion of each activity before the weekly deadline earned up to 10 points toward the course grade.

Mastery quizzes. The mastery quizzes were produced and scored automatically by a collection of Perl scripts written by W. S. Maki. (For information about Perl, see Schwartz, 1998; Stein, 1998; and Wall, Christiansen, \& Schwartz, 1996.) All quiz items were multiple-choice questions taken, with permission, from a test bank furnished by the publisher of the textbook. Two pools of items were formed by the split-half (odd-even) method; one pool was randomly assigned to the quizzes, and the other pool was used for midterm and final examinations. A database was created for each student and updated automatically, recording questions the student had answered correctly, questions answered incorrectly, and "new" questions not yet encountered. When a student requested a quiz for a particular chapter, 15 items were drawn randomly from the pool for that chapter; if no new items remained, the draw was biased toward questions previously answered incorrectly. After all questions had been answered, the quiz was scored and the student was provided with immediate feedback on each item in the quiz. Each alternative for each question was accompanied by a reason why that alternative was correct or incorrect. The student also received notice of the percentage correct for that quiz. The criterion for passing a quiz was $80 \%$ correct. The student needed to pass two mastery quizzes before the due date each week; each quiz passed counted 5 points toward the grade. Failure to pass additional mastery quizzes incurred no penalties.

Interactive assignments. The on-line assignments began with a statement of learning objectives and took various forms, depending on the topics covered in particular chapters. For example, "What is Psychology?" involved using the Web to explore the structure of academic psychology departments and faculty interests; "Sensation and perception" involved the on-line measurement of the Poggendorff illusion (implemented as a Java applet). Each assignment ended in a short quiz consisting of five questions covering the learning objectives for that assignment. Each correct answer counted 2 points toward the grade for that assignment (a maximum of 10 points). There was a total of 14 assignments, with the first one being focused on the policies and procedures for the on-line course.

Class meetings. Ten of the meetings, held each Wednesday, were used for review of the week's chapter topics or for discussion of the week's on-line assignment. Attendance at a class meeting and par- 
ticipation in the class discussion counted 10 points toward the course grade. The remaining Wednesday meetings were used early in the semester for orientation sessions and then for the administration of three in-class midterm examinations, one every 3 weeks.

Course information and study aids. Syllabi, grading policies, a "What's new" page, and study aids were posted on the Web site. The study aids included detailed chapter outlines and more focused FAQs and their answers. The FAQs elaborated on points covered in the textbook that students find difficult and were intended to be analogous to an instructor emphasizing points during a lecture. The Web site was configured so that students in the Web sections could access on-line materials in multiple ways. The home page for the course listed links to each of the four Web sections. Selecting a section resulted in a dialogue requesting a user name and a password Successful completion of the dialogue caused the display of the home page for that particular section which contained links to the "syllabus," "study materials," and "course work." (Thereafter, the links to these parts of the on-line course were always available and were displayed in a navigation bar at the top of each page.)

The on-line syllabus contained a table of due dates for the various course activities. For each week, due dates were listed in a row from left to right, in date order for chapter outline, quizzes, assignments, and weekly class meetings. Each of these dates was linked to the appropriate page for the week's chapter. The study materials page contained links to chapter outlines, lists of several FAQs for each chapter, and an on-line glossary (with terms organized both alphabetically and by chapter). Quizzes and assignments could be accessed through either the syllabus or the course work page.

The outline for each chapter was subdivided into Web pages corresponding to each of the two to five major headings in that chapter of the textbook. The main outline page for the chapter contained a list of these headings with links to the corresponding pages. The pages containing the outline subheadings and text also contained links, where appropriate, to FAQs. Each FAQ, both question and answer, was contained on a single page.

Reward manipulation. In one of each instructor's Web sections each semester, a three-item "miniquiz" was attached to the end of each chapter's list of FAQs. In the other Web section, a three-item miniquiz was attached to the end of each chapter outline page containing the list of major chapter headings. (In interpreting the results, it is important to note that it was possible for a student to take the miniquiz without traversing the links to the substance of the outline.) Each week, the miniquiz needed to be completed by the due date for the study materials posted in the course syllabus. Miniquizzes contributed up to 3 points of course credit. Each correct answer counted 1 point toward the course grade.

\section{Grading and Course Credit}

Mastery quizzes were allocated a maximum of 130 points ( 13 chapters $\times 10$ points), and interactive assignments were allocated 140 points ( 14 weeks $\times 10$ points). The in-class meetings were allocated a maximum of 100 points ( 10 meetings $\times 10$ points $)$. The miniquizzes were allocated a maximum of 39 points $(13$ chapters $\times$ 3 points). The remainder of the 860 points were allocated to midterm examinations ( $3 \times 80$ points), the cumulative final examination (150 points), and participation in the Psychology Department human subject pool.

\section{Dependent Measures}

The questions that need to be answered concern the use of study materials and the effects of that use on learning. Patterns of use of the study materials were determined from three measures. First, all quizzes (mastery quizzes, assignment quizzes, and FAQ and outline miniquizzes) were date-time stamped and sent to the instructor by electronic mail, thus producing a record of the students' responses to the due dates. Second, on a midterm course evaluation, students were asked to rate on a 5-point scale how often they used the chapter outline pages and FAQ pages. Third, software controlling the course Web site kept a count of the initial entries to a Web page (hits) during browser sessions. The software did not associate Web page hits with individual students. Hits for pages containing individual FAQs and outline text were summed for each chapter over the days included in that chapter's unit ( 3 or 4 weeks). The hit rate (hits per page per chapter per student) was determined from the number of students taking the examination at the end of that unit.

The consequences of use of the study materials for learning can be determined from two measures: scores on unit exams and scores on the cumulative part of the final examination. On each examination, several questions were selected that were covered in the textbook but that could have been answered on the basis of the FAQs alone; the remaining questions could have been answered on the basis of the more detailed course outlines or the textbook or both.

\section{RESULTS}

The numbers of data sets available for each dependent measure varied depending on return rate (for course evaluations), incomplete questionnaire forms, and attrition. Unless otherwise noted, the data were averaged across instructors and semesters (a practice justified by the lack of significant interactions with these variables). Statistical significance was assessed in analyses of variance including the following factors, as appropriate: method of instruction (Web vs. lecture), reward condition (FAQ vs. outline vs. lecture), Web page (FAQ vs. outline), semester, and instructor. The significance level was set at .05 .

\section{Use of On-Line materials}

Electronic mail records. Use of both types of quizzes, the three-item miniquizzes (at the end of the FAQ and outline pages) and the regular weekly 15 -item quizzes, will be considered here. On the average, $68 \%$ of the students submitted miniquizzes; of those submitted, $92 \%$ were submitted on or prior to the due dates, and $77 \%$ were submitted during the 2 days prior to the due date. In contrast, $95 \%$ of the students submitted regular quizzes with a similar pattern of use: $97 \%$ were submitted on or before the due date, and $68 \%$ were submitted during the 2 days preceding the due date. The same pattern of miniquiz submissions was found, regardless of whether the miniquizzes were attached to the FAQ or to outline pages. That is, students "rewarded" for using FAQs submitted FAQ miniquizzes, and students "rewarded" for using course outlines submitted outline miniquizzes.

Self-reports of Web page use. Table 1 summarizes the mean ratings for each combination of Web page being rated and reward condition. (Note that higher ratings indicate less frequent use.) Overall, students reported using the chapter outlines midway between once per week and once every 3 weeks (i.e., once per examination), whether they were rewarded for outline use or not. However, students with miniquizzes on FAQ pages reported using FAQ pages about once per week, whereas students with miniquizzes on outline pages reported using FAQ pages about once every 3 weeks (once per ex- 
Table 1

Self-Reports of Web Page Use as a Function of Type of Web Page and Reward Condition

\begin{tabular}{lccccc}
\hline & \multicolumn{4}{c}{ Type of Web page } \\
\cline { 2 - 3 } \cline { 5 - 5 } Reward & \multicolumn{2}{c}{ FAQ } & & \multicolumn{2}{c}{ Outline } \\
\cline { 2 - 5 } \cline { 5 - 6 } & $M$ & $S E$ & & $S E$ \\
\hline FAQ & 2.34 & 0.171 & & 2.46 & 0.185 \\
Outline & 2.95 & 0.152 & & 2.50 & 0.165 \\
\hline
\end{tabular}

Note-Data are means and standard errors of ratings in response to questions beginning with "How often do you use ..." The ratings were more than once per week ( 1 ), once per week (2), once every 3 weeks ( 3 ), less than once every 3 weeks (4), or never (5). Data are based on complete sets of data from 111 students $(n=51$ in the FAQ reward condition and $n=60$ in the outline reward condition).

amination). Thus, student self-reports indicate that FAQ, but not outline, usage was differentially affected by the miniquiz contingencies.

Neither effect of reward condition nor that of Web page was reliable $\left[F(1,103)=2.48, M S_{\mathrm{e}}=2.261\right.$, and $\left.F<1\right]$, respectively. However, the interaction of these two variables was significant $\left[F(1,103)=6.98, M S_{\mathrm{e}}=0.609\right]$, and this interaction was not influenced by either instructor or semester (both three-way interaction $F_{\mathrm{s}}<1$ ). Simple main effects analyses confirmed that the use of the FAQ pages by the groups rewarded for outline use was rated as relatively infrequent. The rating of the FAQ page was significantly higher (indicating less frequent use) in the outline reward condition than in the FAQ reward condition $\left[F(1,103)=7.43, M S_{\mathrm{e}}=1,318\right]$, but the two reward conditions did not differ reliably with respect to ratings of the outline page $(F<1)$.

Web page hits. The self-reports of the effect of miniquiz contingencies was confirmed by Web page hits; the hit rates are summarized in Table 2. Outline pages averaged about 0.63 hits per page per chapter per student. In contrast, the hit rate on FAQ pages averaged 0.57 hits for students in the FAQ miniquiz sections but averaged only 0.25 hits for students in the outline miniquiz sections.

Chapters were used instead of subjects to form error terms in the analysis of variance for Web page hits. Both main effects of reward treatment and page were reliable $\left[F(1,96)=10.78, M S_{\mathrm{e}}=0.079\right.$, and $F(1,96)=133.55$, $M S_{\mathrm{e}}=0.02$, respectively]. The interaction implied in Table 2 was also reliable $\left[F(1,96)=96.26, M S_{\mathrm{e}}=0.02\right]$, and it was not influenced significantly by either semester or instructor (both three-way interaction $F \mathrm{~s}<1$ ). Simple main effects analyses confirmed that the hit rate for FAQ pages was significantly lower in the outline reward condition than in the FAQ reward condition $[F(1,96)=112.43$, $\left.M S_{\mathrm{e}}=0.024\right]$, but the comparison was not reliable for the outline pages $\left[F(1,96)=1.48, M S_{\mathrm{e}}=0.075\right]$.

We also examined the frequency of hits on FAQ and outline pages during the 2-week period prior to the final examination. Our assumption is that the use of these materials to review for the cumulative part of the final examination would be reflected in hits on the pages associ- ated with the first three units. The hit rate was negligible for both FAQ and outline pages, averaging less than 0.02 hits per page per student for the entire 2-week period. We will consider the implications of this fact in the Discussion section.

\section{Measures of Learning}

Analyses were restricted to students completing the final examination. In the fall semester, 57 students from the Web sections and 91 students from the lecture sections took the final examination. In the spring semester, 61 students from the Web sections and 68 students from the lecture sections took the final examination. For reasons unknown, more students did not take the final examination in spring $(n=24)$ than in fall $(n=4)$. This additional attrition did not appear biased toward either type of course ( $n=12$ in Web sections and $n=16$ in lecture sections). Note that the numbers of participants contributing data to these analyses are larger than those reported in R. H. Maki et al. (2000) because of different inclusion criteria; R. H. Maki et al. restricted their analyses to students with complete data sets (including results from questionnaires presented at the beginning and end of each section).

Performance on unit examinations. The proportions correct averaged over all four unit examinations are shown in Table 3 for both questions related to FAQs and questions that could be answered from other sources (non-FAQ). The Web sections scored higher than did the lecture sections (as reported in the companion article), and answers to FAQ-related questions were less accurate than answers to questions covering non-FAQ topics. Apparently, the FAQ questions were more difficult than the non-FAQ questions for the lecture group, but exposure to the FAQs reduced that disadvantage (completely in the case of the FAQ miniquiz groups).

An analyses of variance confirmed that, overall, the students in all Web sections combined $(M=0.724)$ performed better on the unit examinations than did the students in the lecture sections $(M=0.670)$; this effect of method of instruction was significant $[F(1,269)=13.62$, $\left.M S_{\mathrm{e}}=0.027\right]$. FAQ questions averaged significantly fewer correct responses than did the non-FAQ questions $\left[F(1,265)=15.66, M S_{\mathrm{e}}=0.003\right]$, and the effect of reward

Table 2

Frequency of "Hits" on Web Pages as a Function of Type of Web Page and Reward Condition

\begin{tabular}{lccccc}
\hline & \multicolumn{3}{c}{ Type of Web page } \\
\cline { 2 - 3 } \cline { 2 - 3 } Reward & \multicolumn{2}{c}{ FAQ } & & \multicolumn{2}{c}{ Outline } \\
\cline { 2 - 3 } \cline { 5 - 6 } FAQ & $M$ & $S E$ & & $S E$ \\
Outline & 0.568 & 0.021 & & 0.602 & 0.038 \\
\hline
\end{tabular}

Note-Data are means and standard errors of hits per chapter per student. An average of 1.0 would result from each student accessing each chapter's page once during a 3-week unit. Means are based on hit rates for 13 chapters for each of two instructors within each of two semesters ( $n=52$ in each reward condition). 
Table 3

Performance on In-Class Examinations as a Function of Item Content and Reward Condition

Content of Examination Items

\begin{tabular}{lccccc}
\hline & \multicolumn{3}{c}{ Content of Examination Items } \\
\cline { 2 - 3 } \cline { 5 - 6 } \multicolumn{1}{c}{ Reward } & $M$ & $S E$ & & \multicolumn{2}{c}{ Non-FAQ } \\
\cline { 2 - 3 } \cline { 5 - 6 } \multicolumn{1}{c}{ FAQ } & .750 & .019 & & .747 & .015 \\
Outline & .695 & .017 & & .715 & .014 \\
None (Lecture) & .646 & .011 & .694 & .009 \\
\hline
\end{tabular}

Note-Data are average proportions correct (and standard errors) for items pertaining to topics covered in the FAQ versus topics covered in other, "non-FAQ," ways (the course outlines and textbook). Data were averaged over the four unit examinations and are based on participants completing the final examination ( $n \mathrm{~s}=54,64$, and 159 in the FAQ, outline, and lecture conditions, respectively).

condition was also significant $\left[F(2,265)=8.91, M S_{\mathrm{e}}=\right.$ 0.027 ]. The convergence between non-FAQ and FAQ scores with increasing exposure to FAQs shown in Table 3 was also reliable and was indicated by the significant interaction between reward condition and type of question $\left[F(2,265)=8.70, M S_{\mathrm{e}}=0.003\right]$. Simple main effects analyses showed that the difference between non-FAQ and FAQ items $(0.048)$ was reliable in the lecture condition $\left[F(1,155)=49.72, M S_{\mathrm{e}}=0.003\right]$, but the small difference in the opposite direction $(-0.003)$ was not reliable in the FAQ reward condition $(F<1)$; the difference between FAQ and non-FAQ questions was intermediate $(0.020)$ in the outline condition and approached significance $\left[F(1,60)=3.62, M S_{\mathrm{e}}=0.002, p=.062\right]$. The interaction between reward condition and type of question was similar for both semesters and for instructors [largest three-way or four-way interaction $F(2,265)=1.48, M S_{\mathrm{e}}=$ $0.003]$.

Performance on cumulative final examination. Average proportions correct on the cumulative portion of the final examination are shown in Table 4 for FAQ and nonFAQ items. As is observed in the companion article, the difference favoring the Web section was not present on the cumulative part of the examination. The only significant effect was that for type of question, indicating that the advantage of FAQ study shown for the unit tests did not persist to the cumulative final examination.

The overall difference favoring non-FAQ items $(.755$ correct) over FAQ items (.694 correct) was reliable $\left[F(1,265)=25.68, M S_{\mathrm{e}}=0.015\right]$. The reward conditions (FAQ vs. outline vs. lecture) were not reliably different $\left[F(1,265)=1.68, M S_{\mathrm{e}}=0.036\right]$, and the interaction of reward condition and type of item was not reliable either $(F<1)$.

\section{DISCUSSION}

Taraban et al. (1999) reported that students do not use on-line study materials in the manner intended by instructors. Taraban et al. showed that, regardless of the level of technology used in the course, a variety of measures revealed that students deferred use of study aids until the few days prior to an examination. In the project described here, we tried to encourage students to use such materials for preview by providing miniquizzes as rewards. We were partly successful in leading students to those Web pages; students in the FAQ miniquiz groups used the FAQ pages more than did the students in the outline miniquiz groups. We also were partly successful in showing that the increased use of on-line study materials influenced the amount learned. The differential use of the FAQ pages translated into gains in unit test performance on items related to FAQs. However, four aspects of our results constrain our conclusions.

First, the gains in examination performance were short lived; performance on the cumulative part of the final examination did not show any effect of the differential use of FAQ pages. Perhaps knowledge of specific facts acquired during study of the FAQs for individual units did not persist throughout the course. Another possibility arises from the different contingencies in place for weekly work versus review for the final examination. Students in the sections in the FAQ miniquiz condition were rewarded for studying FAQs each week. However, no such contingency was in force for the final examination. Consequently, we saw very little use of study materials for review prior to the final examination, and that lack of review may have resulted in no advantage for the FAQ miniquiz groups on the final examination.

Second, the pattern of effects of miniquiz contingencies on FAQ use and learning was absent for chapter outline use and performance on the "other" examination items. The asymmetry might have been caused by the navigational structure of the Web site. The syllabus page contained links to chapter outlines for all the Web sections, and FAQs could be reached from links on the outline pages. Quite possibly this structure resulted in the same degree of access to, use of, and learning about outline topics in all the Web sections, but only the students in sections exposed to the FAQ miniquiz contingencies might have gone deeper into the Web site seeking information on FAQ pages.

Third, the impact of the differential use of FAQ pages on test performance may have been diminished by the relatively low rates of use of study materials. Only $68 \%$ of the students were submitting miniquizzes, whereas $95 \%$

Table 4

Performance on the Cumulative Part of the Final Examination

\begin{tabular}{|c|c|c|c|c|}
\hline \multirow[b]{3}{*}{ Reward } & \multicolumn{4}{|c|}{ Content of Examination Items } \\
\hline & \multicolumn{2}{|c|}{ FAQ } & \multicolumn{2}{|c|}{ Non-FAQ } \\
\hline & $M$ & $S E$ & $M$ & $S E$ \\
\hline FAQ & .725 & .027 & .773 & .017 \\
\hline Outline & .675 & .024 & .730 & .015 \\
\hline None (Lecture) & .683 & .016 & .762 & .010 \\
\hline
\end{tabular}

Note - Data are average proportions correct (and standard errors) for items pertaining to topics covered in the FAQ versus topics covered in other, "non-FAQ," ways (the course outlines and textbook). Only data from the cumulative part of the final examination are included. Means are based on 54 (FAQ), 64 (outline), and 159 (lecture) scores. 
were submitting regular weekly quizzes. The lower use of study materials may have been caused by the lower course credit value attached to the miniquizzes ( 3 possible points/week vs. 10 possible points/week). This observation suggests that designers of Web courses should consider carefully the valuation of various on-line activities and how the distribution of value will affect the allocation of students' time.

The fourth constraint on our conclusions arises from the possible effects of selection and attrition. Because the Web sections were advertised in the schedule of classes, it is possible that students in the Web sections differed from students in the lecture sections at the beginning of the course. R. H. Maki et al. (2000) note that students did differ on self-reports of Web use and attitudes about computers. For example, students in the Web sections reported both a greater belief that computers increase work efficiency and a greater preexisting use of the Web. R. H. Maki et al. also report that the attrition was significantly greater in the Web sections than in the lecture sections. Both these factors may limit the conclusions drawn about the causes of the difference in learning favoring the Web sections over the lecture sections. However, these factors should be less threatening to conclusions drawn from comparisons only involving the Web sections, because these sections were all advertised in the same way. To check on the equivalence of the Web sections, an additional set of analyses was performed. The data from selfreports of computer use collected during a pretest at the beginning of each semester (see R. H. Maki et al., 2000) were retrieved for the students who did not take the final examination as well as for those who did. The data were sorted into four groups defined by a $2 \times 2$ factorial design, with reward condition (FAQ vs. outline) and attrition (final examination present or absent) as factors. The analyses showed that the two reward conditions were not significantly different on any measure of computer use [largest $\left.F(1,129)=2.30, M S_{\mathrm{e}}=0.15\right]$. Moreover, the interactions of reward condition and attrition also were not significant (all $F_{\mathrm{s}}<1$ ). Thus, as best as we can tell from the pretest data, the Web sections were equivalent groups at the beginning of each semester.

Web courses have the potential to increase our knowledge of student learning behaviors. We observed, for example, that the pattern of miniquiz submissions approximated the pattern of mastery quiz submissions; in both cases, the majority of the submissions occurred during the 2 days preceding the due date. We also observed that the proportion of students submitting miniquizzes averaged just .68. As noted above, that proportion is lower than that observed for the mastery quizzes (.95). However, the Web page hit rates shown in Table 2 are lower yet. This discrepancy implies that some students were submitting miniquizzes without viewing the FAQs or outlines. (The hierarchical structure of the outline pages may have been responsible; the link to the miniquiz was at the same level as links to different parts of the outline, and links to FAQs were embedded in the body of the outline.) Our observations here may prompt a concern over a loss of control of student behaviors in distance learning courses. In response, we point out that we really have little control over student behaviors in any course, regardless of its format and delivery method. The increased measurements enabled by Web-related technology lets us observe student behaviors more closely than in traditional courses.

In general, our results, together with those of Taraban et al. (1999), highlight the importance of allocation of course credit to on-line activities and the rules by which students obtain such credit. Moreover, our data hint at the possible interaction of those contingencies and the navigational structure of an on-line course. If these behavioral factors are not taken into account in the design of on-line courses, we risk building rich cognitive aids that go unused.

\section{REFERENCES}

BoRk, A. (1997). The future of computers and learning. Technological Horizons in Education, 24, 69-77.

DEDE, C. (1996). The evolution of distance education: Emerging technologies and distributed learning. American Journal of Distance Education, 10, 4-36.

Dillon, A., \& Gabbard, R. (1998). Hypermedia as an educational technology: A review of the quantitative research literature on learning comprehension, control, and style. Review of Educational Research, 68, 322-349.

Makı, R. H., Maki, W. S., PatTerson, M., \& Whittaker, P. D. (2000). Evaluation of a Web-based introductory psychology course: I. Learning and satisfaction in on-line versus lecture courses. Behavior Research Methods, Instruments, \& Computers, 32, 230-239.

Makı, W. S., \& MAKI, R. H. (1997). Learning without lectures: A case study. IEEE Computer, 30, 107-108.

Merisotis, J. P., \& PhipPs, R. A. (1999, May/June). What's the difference? Outcomes of distance vs. traditional classroom-based learning. Change, 31, 13-17.

SChWARTZ, A. (1998). Tutorial: Perl, a psychologically efficient reformatting language. Behavior Research Methods, Instruments, \& Computers, 30, 605-609.

StEIN, L. (1998). Official guide to programming with CGI.pm. New York: Wiley.

Taraban, R., Maki, W. S., \& Rynearson, K. (1999). Measuring study time distributions: Implications for designing computer-based courses. Behavior Research Methods, Instruments, \& Computers, 31 , 263-269.

TWIGG, C. A. (1999). Improving learning \& reducing costs: Redesigning large-enrollment courses [On-line]. Troy, NY: Rensselaer Polytechnic Institute, The Pew Learning and Technology Program, Center for Academic Transformation. http://www.center.rpi.edu.

Wall, L., Christiansen, T., \& Schwartz, R. L. (1996). Programming Perl (2nd edition). Sebastopol, CA: O'Reilly \& Associates.

(Manuscript received November 4, 1999;

revision accepted for publication February 28,2000 .) 